\title{
A pesquisa histórica sobre o Brasil nos arquivos dos Estados Unidos: identificação preliminar e projeto de compilação
}

\section{PAULO ROBERTO DE ALMEIDA e FRANCISCO ROGIDO FINS}

O primeiro representante diplomático do Brasil nos Estados Unidos, José Silvestre Rebelo, ministro em Washington de 1824 a 1829, pediu, de volta ao País, que o Legislativo autorizasse o Ministro dos Negócios Estrangeiros a mandar adidos ao estrangeiro a fim de copiar manuscritos importantes relativos ao Brasil. A proposta, junto com as instruções para o primeiro adido, foi aprovada, segundo consta da ata de uma das primeiras sessões do Instituto Histórico e Geográfico Brasileiro, criado em 1838 em torno da idéia de promover a história e o conhecimento geográfico da Pátria ${ }^{1}$.

Rebelo tinha em mente antes os países ibéricos e os demais países europeus do que os Estados Unidos, já que a jovem república americana ostentava, então, uma história de autonomia política apenas algumas décadas mais longa do que a do próprio Império do Brasil. Assim foi feito: o primeiro pesquisador público brasileiro, José Maria do Amaral, foi removido da Legação em Washington, por decreto de 23 de agosto de 1939, para as de Madri e Lisboa, a fim de, segundo informa José Honório Rodrigues, "coligir documentos que pudessem interessar à história do Brasil, na conformidade das instruções que enviaria o Instituto Histórico e Geográfico Brasileiro, com o qual deveria manter-se em constante e direta correspondência”. Mas Amaral, nas palavras de Honório, "não estava preparado para essas tarefas, ao contrário de Varnhagen, que o [iria] substituir”" . Varnhagen, nomeado adido de primeira classe em Lisboa em 1842, passa o restante dessa década na capital portuguesa e em Madri, fazendo anotações nos arquivos e copiando documentos que ele julgava relevantes para a nossa história política. Daí resultaria a História Geral do Brasil, publicada entre 1854 e 1858, quando Varnhagen já tinha sido nomeado secretário do Instituto.

De fato, as principais fontes para a história colonial brasileira encontramse nos arquivos portugueses e espanhóis, complementados pelos da França, dos Países Baixos, da Inglaterra e da Itália, como confirmado pela seleção de países integrantes da primeira fase do Projeto Resgate "Barão do Rio Branco" que, sob a coordenação do Ministério da Cultura (contando com a orientação técnica de 
Esther Caldas Bertoletti), vem efetuando a compilação da documentação histórica sobre o Brasil colonial existente no exterior. O Projeto Resgate, estimulado pelas comemorações dos 500 anos do descobrimento, realizou um magnífico empreendimento que resultou na publicação, em cooperação com as secretarias estaduais de cultura, fundações locais e universidades, de coleções inteiras de documentos manuscritos avulsos e em códices, coletados basicamente nos arquivos portugueses. Os documentos originais foram microfilmados e depois digitalizados, tendo sido oferecidos a bibliotecas e universidades em formato de CD-ROMs, acompanhados dos respectivos catálogos impressos. O Projeto Resgate encontrase igualmente publicando guias das fontes primárias sobre o Brasil colonial nos arquivos europeus mais importantes nessa área: holandeses, espanhóis, franceses e italianos.

Se a história colonial do Brasil pode, a rigor, dispensar a consulta a arquivos americanos (a despeito de algumas excelentes coleções de manuscritos e de obras raras relativas ao período, existentes na Library of Congress ou em bibliotecas universitárias como a John Carter Brown ou a Oliveira Lima), o período independente e, sobretudo, o republicano não podem, em qualquer hipótese, excluir as fontes primárias existentes nos Estados Unidos. Os dois países têm uma longa história de relações diplomáticas, que vem desde antes da independência (o primeiro ministro americano se instalou no Rio de Janeiro em 1809) e se prolonga até os dias de hoje (com algumas breves interrupções no período monárquico). Dada a intensidade dos vínculos econômicos, culturais, militares e de vários outros tipos, não se pode negar a importância dos Estados Unidos para a história brasileira do último século.

Consciente desse fato, a Embaixada do Brasil em Washington, que por iniciativa do Embaixador Rubens Antônio Barbosa já lançou programas ou centros de estudos brasileiros nas universidades de Georgetown e Columbia e está coordenando a edição do Guide to the Study of Brazil in the United States, 1945-2000, está propondo a abertura de um novo capítulo no Projeto Resgate, dedicado desta vez às fontes primárias existentes nos arquivos americanos. Como escreveu ele, "São milhares de páginas — a maior parte já microfilmada — que, pela densidade analítica e por sua importância intrínseca (dada a centralidade dos ESTADOS UNIDOS na história brasileira, sobretudo depois dos anos 30), apresentam interesse para os pesquisadores dedicados ao estudo da inserção do Brasil no cenário mundial e a questões variadas do próprio ambiente doméstico”3 . Em contraste favorável com a relativa dispersão dos arquivos europeus, os mais importantes papéis americanos encontram-se concentrados nos National Archives and Records Administration (NARA), localizado em College Park, no estado de Maryland, região metropolitana de Washington. Os documentos relativos ao Departamento de Estado no NARA foram ou estão sendo microfilmados (http://www.nara.gov/publications/microfilm/diplomatic/diplo-7.html). 
Graças aos esforços empreendidos em meados dos anos 80 pelo sociólogo Luciano Martins, hoje embaixador do Brasil em Havana, boa parte dessa documentação microfilmada já se encontra disponível no Brasil. Citando ainda o embaixador Barbosa: “O Arquivo do Itamaraty possui os primeiros papéis diplomáticos produzidos na capital brasileira, desde 1809 até 1906, ademais de expedientes consulares emanados de dez postos, com destaque para o próprio Rio de Janeiro. O Arquivo Nacional conserva outra série de papéis diplomáticos, desde 1910 até 1959, com exceção dos expedientes relativos ao período da Segunda Guerra” e do período 1906-1910, cujos microfilmes a Embaixada pretenderia adquirir tão pronto logre obter recursos. O material disponível para consulta no Brasil pode ser conferido no link http://www.brasilemb.org/arquivos/.

Uma outra parte da documentação do NARA com relevante potencial para uma pesquisa sobre aspectos diversos da história do Brasil ainda não foi microfilmada ou não está devidamente catalogada em bases geográficas. Encontram-se eventualmente nessa situação papéis do Tesouro (os arquivos se estendem de 1775 a 1990), do Departamento do Comércio (1898-1982), do Eximbank (1933-1975), da Comissão de Energia Atômica (1923-75), da International Trade Commission (1882-1971), dos antecessores do US-Trade Representative (1934-78), sem esquecer os arquivos presidenciais (como os de Truman, Eisenhower, Kennedy, Johnson, Carter e Reagan, para ficar nos mais conhecidos) e os papéis da própria CIA, cujos antecedentes funcionais remontam a 1894. Estes últimos podem ser requisitados para consulta mediante o dispositivo do Freedom of Information Act (FOIA), mas o prazo para que os documentos sejam liberados após a requisição pode variar, por razões administrativas, de três a seis meses. A implementação do Projeto Resgate-EUA poderia completar as lacunas existentes na documentação, por meio de um apelo sistemático ao FOIA nas séries relevantes.

A Embaixada em Washington está realizando um levantamento preliminar sobre o conjunto das fontes documentais do NARA sobre o Brasil e pretenderia, mediante a implementação de um Projeto Resgate-EUA, realizar as seguintes tarefas:

(a) identificação precisa dos arquivos existentes e sua quantificação preliminar, nos formatos disponíveis (microfilmes, textuais, iconografia, audiovisuais);

(b) preparação de um Guia sintético realizando esse inventário para fins de informação dirigida à comunidade dos pesquisadores brasileiros e à sociedade civil;

(c) catalogação descritiva dessas fontes primárias, envolvendo, numa primeira etapa, a documentação diplomática, estendendo-se posteriormente a arquivos adicionais; 
(d) aquisição dos microfilmes disponíveis no NARA, bem como reprodução de material relevante ainda não microfilmado, segundo escala de prioridades a ser definida (iniciando provavelmente pelo material dos anos 60).

Com base na catalogação será possível iniciar-se a reprodução dos documentos ainda não disponíveis no Brasil, sua transferência a arquivos brasileiros e sua transposição em formato digital. A documentação assim recolhida poderá ser colocada à disposição dos arquivos brasileiros (Arquivo Nacional e Arquivo Histórico Diplomático), da Biblioteca Nacional, bem como, mediante sua reprodução em meio eletrônico, de outros centros de pesquisa e universidades interessadas. Ele deverá igualmente integrar a base de dados do Projeto Resgate, que está sendo preparada pelo MinC para divulgação via Internet. O Projeto Resgate-EUA, cuja efetivação depende da obtenção de recursos de fontes oficiais e privadas, pode ser visto como uma demonstração da dedicação e seriedade com que iniciativas de tipo acadêmico vem sendo conduzidas pela Embaixada do Brasil em Washington.

Abril de 2001

\section{Notas}

1 Sessão de 7 de junho de 1839, in Revista do IHGB, t. 1, pp. 151, 257-59, apud José Honório Rodrigues, A Pesquisa Histórica no Brasil, $3^{\text {a }}$ ed., São Paulo : Companhia Editora Nacional; Brasília, INL, 1978, p. 39.

2 Cf. Rodrigues, op. cit., p. 39.

3 Cf. Rubens A. Barbosa, “A história do Brasil nos arquivos dos Estados Unidos”, Folha de São Paulo, 16.02.2001, p. 3, também em: http://www.brasilemb.org/arquivos/01_apresenta.htm. 